\title{
Control of Interspecies Electron Transfer Flow during Anaerobic Digestion: Dynamic Diffusion Reaction Models for Hydrogen Gas Transfer in Microbial Flocs
}

\author{
Sadettin S. Ozturk* and Bernhard O. Palsson \\ Department of Chemical Engineering, University of Michigan, Ann Arbor, \\ Michigan 48109-2136 \\ Jurgen $H$. Thiele \\ Michigan Biotechnology Institute, 3900 Collins Road, P.O. Box 27609, \\ Lansing, Michigan 48909
}

Accepted for publication April 22, 1988

\begin{abstract}
Dynamic reaction diffusion models were used to analyze the consequences of aggregation for syntrophic reactions in methanogenic ecosystems. Flocs from a whey digestor were used to measure all model parameters under the in situ conditions of a particular defined biological system. Fermentation simulations without adjustable parameters could precisely predict the kinetics of $\mathrm{H}_{2}$ gas production of digestor flocs during syntrophic methanogenesis from ethanol. The results demonstrated a kinetic compartmentalization of $\mathrm{H}_{2}$ metabolism inside the flocs. The interspecies electron transfer reaction was mildly diffusion controlled. The $\mathrm{H}_{2}$ gas profiles across the flocs showed high $\mathrm{H}_{2}$ concentrations inside the flocs at any time. Simulations of the syntrophic metabolism at low substrate concentrations such as in digestors or sediments showed that it is impossible to achieve high $\mathrm{H}_{2}$ gas turnovers at simultaneously low steady-state $\mathrm{H}_{2}$ concentrations. This showed a mechanistic contradiction in the concept of postulated low $\mathrm{H}_{2}$ microenvironments for the anaerobic digestion process. The results of the computer experiments support the conclusion that syntrophic $\mathrm{H}_{2}$ production may only be a side reaction of $\mathrm{H}_{2}$ independent interspecies electron transfer in methanogenic ecosystems.
\end{abstract}

\section{INTRODUCTION}

Anaerobic waste treatment systems generate increasing interest because of their simple operation and the production of methane as a byproduct credit. ${ }^{1-3}$ Fast and stable high-rate digestors are important to increase the applicability of this technology, and this requires a complete understanding of the process dynamics on a microbiological and molecular level. It is presently believed that the biomethanation of organic matter depends on the concerted action of at least three different trophic groups of bacteria: (I) hydrolytic bacteria, (II) syntrophic acetogenic bacteria, and (III)

\footnotetext{
* To whom all correspondence should be addressed.
}

methanogenic bacteria. ${ }^{4-6}$ Hydrolytic bacteria ferment waste material to organic acids and alcohols, and these fermentation products are converted to acetate and reducing equivalents $\left(\mathrm{XH}_{2}\right)$ by syntrophic acetogens. ${ }^{6,7}$ Methanogenic bacteria cleave acetate to methane and $\mathrm{CO}_{2}$ and utilize $\mathrm{XH}_{2}$ for $\mathrm{CO}_{2}$ reduction to methane. ${ }^{8,9}$ Syntrophic (syn: greek together, trophein: greek eat) acetogens and methanogenic bacteria communicate by an environmental process called interspecies $\mathrm{H}_{2}$ transfer. The concept is based on the observation that syntrophic acetogenic bacteria cannot grow in the absence of $\mathrm{XH}_{2}$-oxidizing bacteria. ${ }^{10-12}$ The syntrophy is mutual because methanogenic bacteria require acetate and $\mathrm{XH}_{2}$ for growth and metabolism. The growth rate of acetogens and methanogens depends thus on the efficiency of $\mathrm{XH}_{2}$ transfer. An immobilization of juxtaposed bacteria of the different trophic groups ${ }^{7,8}$ should therefore stimulate the overall conversion rate and growth rates in the ecosystem. A bacterial immobilization is often used for biofilm, floc, and granule formation in advanced anaerobic waste treatment processes. ${ }^{13-15}$ Better process stability is observed, and the washout of slow-growing bacteria is minimized. But mass transfer limitations of carbon precursors from the bulk into the aggregates could occur as a consequence of aggregation, ${ }^{16,17}$ and temporary inhibitory levels of reaction intermediates such as $\mathrm{XH}_{2}$ could build up within such aggregates.

Chartrain and Zeikus ${ }^{5,13,18}$ studied the biomethanation of whey in a model digestor. Ethanol was a major reaction intermediate besides lactate. Both substrates were syntrophically converted to acetate and methane, and more than 75\% of the syntrophic metabolism of ethanol in this digestor was associated with bacterial flocs. ${ }^{7}$ The flocs contained a mixture of microorganism with Desulfovibrio vulgaris and Methanobacterium formicicum as the prevalent syntrophic acetogenic and methanogenic species. Both 
species dominated their individual trophic groups at least 100fold. ${ }^{13,18}$ Microcolonies of single species were not found. ${ }^{7,18}$ Thus the flocs could be considered as homogeneous defined biocatalysts composed of an immobilized consortium of syntrophic acetogenic and methanogenic bacteria.

It was proposed recently that lower levels of $\mathrm{H}_{2}$ gas around acetogenic bacteria were established in nature by very active methanogenic $\mathrm{H}_{2}$ consumption within microbial aggregates. ${ }^{19}$ This could result in compartmentalized $\mathrm{H}_{2}$ metabolism and enhanced syntrophic acetogenesis. It was also shown that more than $95 \%$ of the $\mathrm{H}_{2}$ metabolism in anaerobic digestors and lake sediments could not be explained by the turnover of the $\mathrm{H}_{2}$ gas pool. ${ }^{20}$ This supported the speculation that the $\mathrm{H}_{2}$ gas metabolism was compartmentalized within microbial aggregates, but the data could also be explained by a $\mathrm{H}_{2}$-gas-independent mechanism of anaerobic syntrophy in the sediments. ${ }^{21}$ Boone, on the contrary, assumed for a mixed culture fermentor the existence of particles with high internal fermentative $\mathrm{H}_{2}$ metabolism and methanogenesis. ${ }^{22}$ This should avoid $\mathrm{H}_{2}$ gas production in the ecosystem and keep the $\mathrm{H}_{2}$ partial pressure outside the particles low enough to allow for syntrophic acetogenesis. Recently we showed by disintegration of digestor flocs that the interspecies electron transfer was compartmentalized inside the flocs and that more than $95 \%$ of the syntrophic metabolism could have been $\mathrm{H}_{2}$ gas independent. ${ }^{?}$ Elsewhere we present experimental biochemical, ecological, and modeling evidence that interspecies electron transfer in these aggregates could occur by acetogenic $\mathrm{CO}_{2}$ reduction to formate. ${ }^{23}$ This interspecies electron transfer mechanism avoids direct acetogenic $\mathrm{H}_{2}$ gas production and is consistent with all existing experimental evidence about syntrophic associations. ${ }^{21}$ Thus many different speculations are presently supported by few consistent data.

The lack of measurement techniques for $\mathrm{H}_{2}$ gas within microbial aggregates at the ppm level prohibits the experimental proof of the prevalent syntrophic mechanisms. Realistic reaction diffusion models could therefore extend the present analytical capabilities from bulk measurements into the floc compartment and would be useful to test the different proposed mechanisms. Useful dynamic reactiondiffusion models based on Michaelis-Menten kinetics were derived and reported by us earlier. ${ }^{24}$ The available experimental data on the apparent $\mathrm{H}_{2}$ production during the syntrophic ethanol metabolism in the whey digestor flocs were suitable to test the model predictions. It is thus the purpose of this communication to apply these simple reaction diffusion models as analytical tools. This was accomplished by comparison of experimental data with model predictions without any adjustable model parameters. A good agreement of model predictions with the experimental data permitted the simulation of the concentration profiles of $\mathrm{H}_{2}$ gas during syntrophic ethanol conversion in the digestor flocs and the testing of the mechanistic consistency of the interspecies $\mathrm{H}_{2}$ gas transfer hypothesis. It was further tested whether predicted $\mathrm{XH}_{2}$ levels in the aggregates would be higher or lower than in the environment to evaluate the different proposed mechanisms of syntrophic coupling during anaerobic digestion.

\section{MODEL DEVELOPMENT AND ANALYTICAL} METHODS

\section{The Reaction Scheme}

The overall reactions in the floc model system with ethanol as a substrate are described by

(a)

$$
\begin{aligned}
& 2 \mathrm{C}_{2} \mathrm{H}_{5} \mathrm{OH}+2 \mathrm{H}_{2} \mathrm{O} \stackrel{\text { acelogenesis }}{\longrightarrow} 4 \mathrm{H}_{2}+2 \mathrm{CH}_{3} \mathrm{COO}^{-}+2 \mathrm{H}^{+} \\
& \text {(b) } 4 \mathrm{H}_{2}+\mathrm{HCO}_{3}^{-}+\mathrm{H}^{+} \stackrel{\text { methanogenesis }}{\longrightarrow} \mathrm{CH}_{4}+3 \mathrm{H}_{2} \mathrm{O}
\end{aligned}
$$

We will use $A$ to denote ethanol $\left(\mathrm{C}_{2} \mathrm{H}_{5} \mathrm{OH}\right), B$ to denote hydrogen $\left(\mathrm{H}_{2}\right), \mathrm{C}$ to denote acetate $\left(\mathrm{CH}_{3} \mathrm{COO}^{-}\right)$, and $E$ to denote methane $\left(\mathrm{CH}_{4}\right)$.

\section{Mathematical Model}

\section{Floc Phase}

Our mathematical treatment will assume that the microbial flocs are spherical* in shape and that the acetogens and methanogens are uniformly distributed throughout these spheres (Fig. 1). Reactant $A$ diffuses into the floc and reacts according to reaction (a). Consequently the concentration of $A$ is lowered inside the floc. Species $B$, the product of reaction (a) either undergoes reaction (b) or diffuses out of the floc. Species $C$ and $E$ diffuse out of the floc into the surrounding liquid medium. Relatively complex concentration profiles, as illustrated in Figure 1, can be obtained for $B$ depending on the relative magnitudes of the reaction rates for reactions (a) and (b).

By using Fick's law for diffusion, the general mass balances on the floc phase for a given species take the form

$$
\frac{\partial \mathcal{C}_{i}}{\partial t}=\frac{D_{i}}{r^{2}} \frac{\partial}{\partial r}\left(r^{2} \frac{\partial C_{i}}{\partial r}\right)+\sum \nu_{i, k} \phi_{k}
$$

where, for species $i, C_{i}$ is the molar concentration, $D_{i}$ is the diffusion coefficient, and $r$ is the radial coordinate. The $k$ th reaction rate is $\phi_{k}, \nu_{i, k}$ is the stoichiometric coefficient of component $i$ in the $k$ th reaction (positive for products, negative for reactants), and $t$ is time.

The changes in the bulk concentrations are of importance for the mass balance of the overall process because the flocs constitute only a small volume fraction $(<2 \%)$. If the transient changes of concentrations inside the flocs are rapid relative to the concentration changes in the bulk, we can assume a quasi-steady-state concentration profile inside the floc. The unsteady-state term, $\partial C_{i} / \partial t$, can then be removed from the mass balance equation for the floc phase:

$$
\frac{D_{i}}{r^{2}} \frac{\partial}{\partial r}\left(r^{2} \frac{\partial C_{i}}{\partial r}\right)+\sum \nu_{i, k} \phi_{k}=0
$$

\footnotetext{
* Extensive results of reaction-diffusion modeling work has shown that in general the results obtained are relatively insensitive to geometry (see ref. 25).
} 

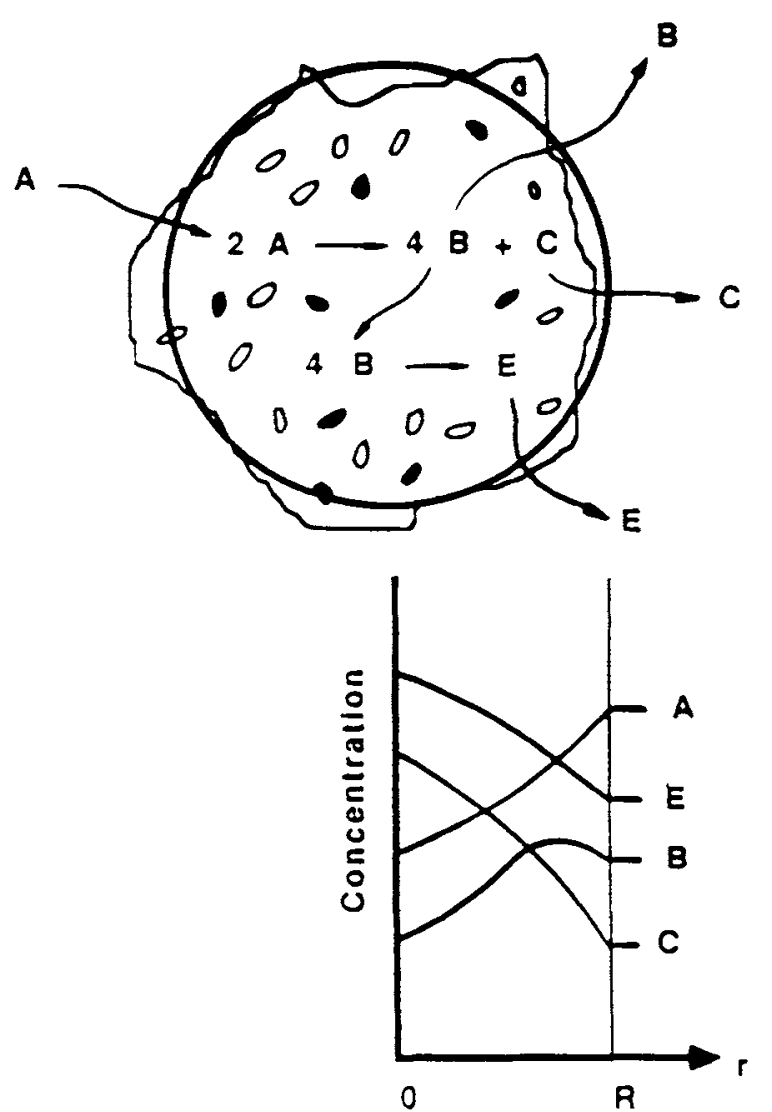

Figure 1. Schematic representation of digestor flocs during syntrophic ethanol conversion. Ethanol (A) diffuses from bulk unto flocs and is converted by acetogenic bacteria to $\mathrm{H}_{2}(\mathrm{~B})$ and acetate (C). The $\mathrm{H}_{2}$ diffuses either into bulk or is utilized for methanogenic $\mathrm{CO}_{2}$ reduction to methane (E). Examples for possible steady-state concentration profiles in insert. Center of floc is at $r=0$, periphery at $r=R$.

This assumption is reasonable since the floc sizes are on the order of $100 \mu \mathrm{m}$, and diffusional response times for a species that has a diffusivity of $10^{-6} \mathrm{~cm}^{2} / \mathrm{s}$ will be approximately

$$
t_{\text {diff }}=\frac{\delta^{2}}{D}=\frac{(0.01 \mathrm{~cm})^{2}}{10^{-6} \mathrm{~cm}^{2} / \mathrm{s}}=100 \mathrm{~s}
$$

which is small compared to the usual digestion time of hours.

The mass balance equations which describe the concentrations in the floc phase are

$$
\begin{aligned}
& \frac{D_{A}}{r^{2}} \frac{d}{d r}\left(r^{2} \frac{d C_{A}}{d r}\right)=\mathbf{r}_{1} \\
& \frac{D_{B}}{r^{2}} \frac{d}{d r}\left(r^{2} \frac{d C_{B}}{d r}\right)=4 \mathbf{r}_{2}-2 \mathbf{r}_{1} \\
& \frac{D_{C}}{r^{2}} \frac{d}{d r}\left(r^{2} \frac{d C_{C}}{d r}\right)=-\mathbf{r}_{1} \\
& \frac{D_{E}}{r^{2}} \frac{d}{d r}\left(r^{2} \frac{d C_{E}}{d r}\right)=-\mathbf{r}_{2}
\end{aligned}
$$

where $\mathbf{r}_{1}$ and $\mathbf{r}_{2}$ are the reaction rates for acetogenesis [reaction (a)] and methanogenesis [reaction (b)], respectively.
The $\mathrm{H}^{+}$concentration is assumed to be uniform since the system is buffered by $\mathrm{HCO}_{3}^{-}(>20 \mathrm{~m} M)$ or $\mathrm{HPO}_{4}^{-2} / \mathrm{H}_{2} \mathrm{PO}_{4}^{-}$ $(50 \mathrm{mM})$. Dissipation of water molecules in the first reaction is neglected.

The boundary conditions for our system are standard:

1. At the floc center $(r=0)$

$$
\frac{d C_{\mathrm{A}}}{d r}=\frac{d C_{B}}{d r}=\frac{d C_{C}}{d r}=\frac{d C_{E}}{d r}=0
$$

This condition implies that the concentration profiles are symmetrical around the center (Fig. 1).

2. At the surface $(r=R)$

$$
C_{A}=C_{A}^{l} \quad C_{B}=C_{B}^{l} \quad C_{C}=C_{C}^{l} \quad C_{E}=C_{E}^{l}
$$

The reaction rates are expressed in Michaelis-Menten form. The acetogenic reaction is inhibited by its product, $\mathrm{H}_{2}$, and the reversibility of the reaction is taken into account by the following form of the rate expression ${ }^{26}$ :

$$
\mathbf{r}_{1}=\frac{k_{1}\left(C_{A}-C_{B}^{2} C_{C} / K_{e q}^{\prime}\right)}{K_{m, A}+C_{A}}
$$

The kinetics of the methanogenic reaction is represented by

$$
\mathbf{r}_{2}=\frac{k_{2} C_{B}}{K_{m, B}+C_{B}}
$$

When the reaction rate expessions are inserted into the differential equations [eqs. (4)-(7)], the final form of the model equations is obtained:

$$
\begin{aligned}
& \frac{D_{A}}{r^{2}} \frac{d}{d r}\left(r^{2} \frac{d C_{A}}{d r}\right)=\frac{k_{1}\left(C_{A}-C_{B}^{2} C_{C} / K_{\mathrm{eq}}^{\prime}\right)}{K_{m, A}+C_{A}} \\
& \frac{D_{B}}{r^{2}} \frac{d}{d r}\left(r^{2} \frac{d C_{B}}{d r}\right)=\frac{4 k_{2} C_{B}}{K_{m, B}+C_{B}}-2 \frac{k_{1}\left(C_{A}-C_{B}^{2} C_{C} / K_{\mathrm{eq}}^{\prime}\right)}{K_{m, A}+C_{A}} \\
& \frac{D_{C}}{r^{2}} \frac{d}{d r}\left(r^{2} \frac{d C_{C}}{d r}\right)=-\frac{k_{1}\left(C_{A}-C_{B}^{2} C_{C} / K_{\mathrm{eq}}^{\prime}\right)}{K_{m, A}+C_{A}} \\
& \frac{D_{E}}{r^{2}} \frac{d}{d r}\left(r^{2} \frac{d C_{E}}{d r}\right)=-\frac{k_{2} C_{B}}{K_{m, B}+C_{B}}
\end{aligned}
$$

\section{Liquid and Gas Phases}

The liquid phase is assumed to be sufficiently mixed to make external mass transfer resistances insignificant. This assumption was ascertained in the extractive experimental system. ${ }^{7}$ Under these conditions the surface concentration can be considered to be equal to the bulk value, and we can write the following balance equations to describe the variations of the bulk concentrations with time:

$$
V_{L} \frac{d C_{i}^{l}}{d t}=-a_{v} D_{A}\left(\frac{d C_{i}}{d r}\right)_{r=R}-V_{G} \frac{d C_{i}^{k}}{d t}
$$

Gaseous species will be transferred to the gas phase. The mass transfer rate between the gas and liquid phases are 
assumed to be sufficiently rapid as determined experimentally. ${ }^{7}$ Under these conditions we use a quasi-equilibrium condition and write

$$
C_{i}^{g}=m_{i} C_{i}^{l}
$$

where $m_{i}$ is the solubility coefficient for species $i$.

Then, the following mass balance holds for the liquid phase:

$$
V_{L} \beta_{i} \frac{d C_{i}^{l}}{d t}=-a_{v} D_{A}\left(\frac{d C_{i}}{d r}\right)_{r=R}
$$

where

$$
\beta_{i}=1+\left(V_{G} / V_{L}\right) m_{i}
$$

is a constant and related to the distribution coefficient for the volatile component $i$. For nonvolatile components the value of $\beta$ is unity. The initial conditions for these equations are

$$
C_{i}^{l}=C_{i, o}^{l}
$$

The gas phase concentrations can be calculated from equation (17).

\section{Scaling and Extraction of Model Parameters}

Following standard procedures, the equations will now be scaled and the parameters combined into the minimum number of dimensionless property ratios. Using the natural reference scales, $R$ for length, and the $K_{m}$ values for the concentrations, the scaled forms of the flocs phase equations are

$$
\begin{aligned}
\frac{1}{\xi^{2}} \frac{d}{d \xi}\left(\xi^{2} \frac{d a}{d \xi}\right) & =\phi^{2} \frac{a-b^{2} c / \kappa}{1+a} \\
\frac{1}{\xi^{2}} \frac{d}{d \xi}\left(\xi^{2} \frac{d b}{d \xi}\right) & =\psi^{2} \frac{b}{1+b}-\phi^{2} \frac{a-b^{2} c / \kappa}{1+a} \alpha_{1} \gamma \\
\frac{1}{\xi^{2}} \frac{d}{d \xi}\left(\xi^{2} \frac{d c}{d \xi}\right) & =-\phi^{2} \frac{a-b^{2} c / \kappa}{1+a} \alpha_{2} \\
\frac{1}{\xi^{2}} \frac{d}{d \xi}\left(\xi^{2} \frac{d e}{d \xi}\right) & =-\psi^{2} \frac{b}{1+b} \alpha_{3}
\end{aligned}
$$

where the new variables are $\xi=r / R$ as the dimensionless radial coordinate, $a=C_{A} / K_{m, A}, b=C_{B} / K_{m, B}, c=C_{C} /$ $K_{m, A}$, and $e=C_{E} / K_{m, B}$ as the dimensionless concentra- tions. The system is characterized by the seven dimensionless groups shown in Table I.

The dimensionless boundary conditions are as follows:

1. At $\xi=0$ (center)

$$
\frac{d a}{d \xi}=\frac{d b}{d \xi}=\frac{d c}{d \xi}=\frac{d e}{d \xi}=0
$$

2. At $\xi=1$ (surface)

$$
a=a_{\mathrm{o}}, \quad b=b_{o} \quad c=c_{o} \quad e=e_{o}
$$

The dimensionless form of the equations for bulk concentrations are

$$
\begin{aligned}
\frac{d a_{o}}{d \tau} & =-3\left(\frac{d a}{d \xi}\right)_{\xi=1} \\
\alpha_{1} \beta_{b} \frac{d b_{o}}{d \tau} & =-3\left(\frac{d b}{d \xi}\right)_{\xi=1} \\
\alpha_{2} \frac{d c_{o}}{d \tau} & =-3\left(\frac{d c}{d \xi}\right)_{\xi=1} \\
\alpha_{3} \beta_{e} \frac{d e_{o}}{d \tau} & =-3\left(\frac{d e}{d \xi}\right)_{\xi=1}
\end{aligned}
$$

Here $\tau=\epsilon t D_{A} / R^{2}$ is dimensionless time scaled to the diffusional response time and $\epsilon$ is the floc volume fraction in the liquid.

\section{Simplifications and Analytical Solutions for Floc Phase Concentrations}

Consideration of the magnitude of the parameters and the variables in the model equations shows that they may be simplified for an analytical solution. Under the conditions where $a \gg 1, b \ll 1$, and zero- and first-order reaction rates apply for $\mathbf{r}_{1}$ and $\mathbf{r}_{2}$, respectively, because $C_{A}^{l} \gg K_{m, A}$ and $C_{B}^{l} \ll K_{m, b}$

$$
\begin{aligned}
& \frac{1}{\xi^{2}} \frac{d}{d \xi}\left(\xi^{2} \frac{d a}{d \xi}\right)=\phi^{2} \\
& \frac{1}{\xi^{2}} \frac{d}{d \xi}\left(\xi^{2} \frac{d b}{d \xi}\right)=\psi^{2} b-\alpha_{1} \gamma \phi^{2}
\end{aligned}
$$

The solutions to these equations are

$$
a=\frac{\phi^{2}}{6}\left(\xi^{2}-1\right)+a_{o}
$$

Table I. Dimensionless parameters in model equations.

$$
\begin{array}{ll}
\phi^{2}=\frac{k_{1} / K_{m, A}}{D_{A} / R^{2}} & \text { Thiele modulus for first reaction } \\
\psi^{2}=\frac{4 k_{2} / K_{m, B}}{D_{B} / R^{2}} & \text { Thiele modulus for second reaction } \\
\kappa=K_{\text {eq }}^{\prime} / K_{m A}^{2} & \text { dimensionless equilibrium constant } \\
\alpha_{1}=D_{A} / D_{B}, \alpha_{2}=D_{A} / D_{C}, \alpha_{3}=D_{B} / D_{E} & \text { diffusivity ratios } \\
\gamma=K_{m, A} / K_{m, B} & \text { ratio of Michealis constants }
\end{array}
$$




$$
b=\left(b_{o}-\frac{\alpha_{1} \gamma \phi^{2}}{\psi^{2}}\right) \frac{\sinh (\psi \xi)}{\xi \sinh (\psi)}+\frac{\alpha_{1} \gamma \phi^{2}}{\psi^{2}}
$$

where $b_{0}$ is the value of $b$ at the surface, i.e., $C_{B}^{l} / K_{m, B}$. Although these equations are very convenient to use, their limitations must be kept in mind.

\section{General Solution Technique}

The system of four differential equations [eqs. (20)(23)] which comprise the mathematical model for the floc phase is nonlinear and subject to the indicated boundary conditions. An analytical solution to this system is not attainable, and numerical solutions are needed. The equations were solved numerically using the method of orthogonal collocation and orthogonal collocation on finite elements. The concentration-time profiles, on the other hand, were evaluated by the solution of first-order differential equations [eqs. (26)-(29)] after the derivatives are calculated using the standard Runge-Kutta-Gill method to carry out these calculations. ${ }^{27}$ The required derivatives for these equations are obtained from the solution of differential equations (20)-(23).

\section{Estimations of Model Parameters}

\section{Measurements of Diffusivities}

Floc material from a whey digester was collected and separated from free cells by centrifugation. ${ }^{7}$ It was heated at $80^{\circ} \mathrm{C}$ for $10 \mathrm{~min}$ to stop all biological activity. The flocs were resuspended in a phosphate buffer $(0.0816 M, \mathrm{pH} 7.0)$ containing $500 \mu \mathrm{M} \mathrm{HgCl}_{2}$. No biological activity to degrade ethanol, acetate, and $\mathrm{H}_{2}$ gas and to form methane was found. After centrifugation at $100,000 \mathrm{~g}$ for $30 \mathrm{~min}$ a paste was obtained. This floc paste was assumed to have a similar composition and structure to the flocs in the digester.

The diffusivity of ethanol and acetate in the floc paste was determined in a diffusion cell of $50 \mathrm{~mL}$ (Fig. 2A).

The floc paste was placed into a circular plexiglass spacer between two filter disks (Millipore, Bedford, MA, pore size $0.45 \mu \mathrm{m})$. The spacer was $2 \mathrm{~mm}$ thick with a diameter of $3 \mathrm{~cm}$. Two sintered glass disks ( $3 \mathrm{~mm}$ thick) were used to hold the spacer between the chambers. Magnetic stirrers were used to mix the contents of the chambers.

The chambers were filled with a phosphate buffer (0.0816M, pH 7) containing $500 \mu M \mathrm{HgCl}_{2}$. A known amount of ethanol and acetate were injected to one side, and samples from the injection and receiver sides were taken. During sampling $0.5 \mathrm{~mL}$ content was replaced with the original buffer solution to maintain constant volume and was accounted for in the analysis. The samples were acidified with $\mathrm{H}_{3} \mathrm{PO}_{4}$ ( $1 \mathrm{~N}$ final) and subsequently analyzed according to standard techniques. ${ }^{7}$ Experiments were run for 5-7 days and sampling time was varied between 12 and $24 \mathrm{~h}$.

A mass balance calculated during the experiment showed the absence of significant ethanol and acetate consumption in the diffusion cell.

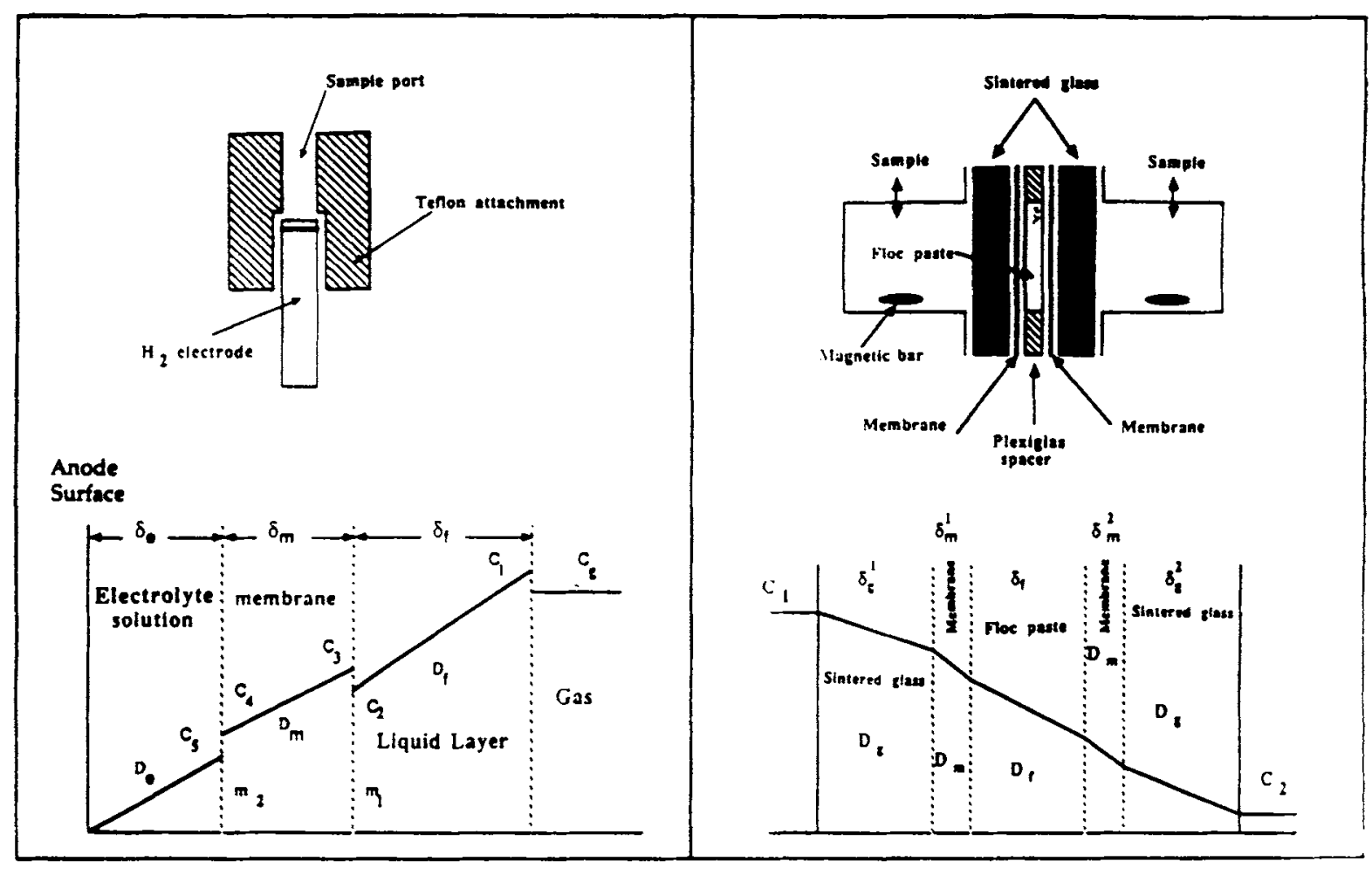

(a)

(b)

Figure 2. Principles of experimental setups for diffusivity determinations of gaseous and dissolved biological intermediates. Expected concentration profiles shown in lower portion of figures. (A) Hydrogen electrode with attachment. (B) Diffusion cell. 
For the analysis of the experimental data for the diffusion coefficients, a quasi-steady-state condition was assumed. Referring to Fig. 2A, the flux of a species, $J$, is given by

$$
J=K_{\mathrm{eff}}\left(C_{1}-C_{2}\right)
$$

where

$$
\frac{1}{K_{\text {eff }}}=\frac{\delta_{g}^{1}+\delta_{g}^{2}}{D_{g}}+\frac{\delta_{m}^{1}+\delta_{m}^{2}}{D_{m}}+\frac{\delta_{f}}{D_{f}}=\frac{1}{K_{\text {sys }}}+\frac{1}{K_{\text {floc }}}
$$

It is assumed that the compound is equally soluble in the liquid and floc phase and insoluble in the glass and the membrane.

Then the mass balances for injection and receiver sides become

$$
\begin{aligned}
-V_{1} \frac{d C_{1}}{d t} & =K_{\text {eff }} A\left(C_{1}-C_{2}\right) \\
V_{2} \frac{d C_{2}}{d t} & =K_{\text {eff }} A\left(C_{1}-C_{2}\right)
\end{aligned}
$$

Integration of these equations and noting that the volumes are identical, i.e., $V=V_{1}=V_{2}$, we get

$$
\ln \left(\frac{C_{T}-2 C_{2}}{C_{T}-2 C_{2}^{o}}\right)=2 \frac{K_{\mathrm{eff}} A t}{V}
$$

where $C_{T}$ is the total initial concentration, i.e., $C_{T}=$ $C_{1}^{o}+C_{2}^{o}$.

Equation (38) was used in a difference form, between two sampling points:

$$
\ln \left(C_{T}-2 C_{2}\right)-\ln \left(C_{\Upsilon}-2 C_{2}^{o}\right)=2 \frac{K_{\mathrm{eff}} A \Delta t}{V}
$$

For the determination of the constant $K_{\text {sys }}$, the spacer was removed and measurements were done with filter papers and sintered glasses only. The diffusivity in the floc phase $\left(D_{f}\right)$ was then extracted from the $K_{\text {floc }}$ value eq. (35)] together with the information on the thickness of the paste $\left(\delta_{f}\right)$.

The diffusivity of $\mathrm{H}_{2}$ gas was measured in analogy to the determination of the $\mathrm{O}_{2}$ diffusivity based on the measurement of steady-state concentrations. ${ }^{28,29}$ A Clark electrode (Diamond Electrotech, Ann Arbor, MI) was modified to measure $\mathrm{H}_{2}$ amperometrically. A Teflon attachment with an inner diameter of $3 \mathrm{~mm}$ and a length of $5 \mathrm{~mm}(0.141$ $\mathrm{cm}^{3}$ void volume) was manufactured and placed on top of the electrode to hold the floc paste (Fig. 2B). The electrode with the attachment on it was enclosed in a temperaturecontrolled jacket. The total volume was $14 \mathrm{~mL}$. The gas phase was kept in contact with the electrode as the jacket was closed by two stoppers. A small amount of water ( $1 \mathrm{~mL}$ ) was added at the bottom and a wetted tissue was placed at the side of the attachment to prevent the paste from drying. The jacket was made anaerobic by repeated evacuation and flushing with $100 \% \mathrm{~N}_{2}$ passed over hot copper filings.
The jacket was connected to a circulating waterbath and after temperature equilibration to $37^{\circ} \mathrm{C}, \mathrm{H}_{2}$ was injected into the gas phase by a syringe simultaneously using a second syringe to avoid pressure changes. The gases were mixed and the gas composition (40-60\%) of $\mathrm{H}_{2}$ was measured by gas chromotography using a Hewlett-Packard 5890A gas chromatograph equipped with a thermal conductivity detector. Electrode signals were amplified and recorded. After a certain time a steady-state $\mathrm{H}_{2}$ transfer to the electrode surface was reached (Fig. 3). The consumption of $\mathrm{H}_{2}$ during the experiments was found to be negligible. Calibrations of the electrode were carried out immediately after the experiments.

The data analysis assumes that the $\mathrm{H}_{2}$ gas diffuses to the anode surface and is rapidly oxidized. If the process is diffusion limited, the following expression for the flux of $\mathrm{H}_{2}$ is valid:

$$
J=K_{\text {eff }} C_{l}=K_{\text {eff }} \frac{C_{g}}{m}
$$

where

$$
\frac{1}{K_{\mathrm{eff}}}=m_{1}\left(\frac{\delta_{m}}{D_{m}}+m_{2} \frac{\delta_{e}}{D_{e}}\right)+\frac{\delta_{f}}{D_{f}}=\frac{1}{K_{\mathrm{sys}}}+\frac{1}{K_{\mathrm{floc}}}
$$

and $C_{l}$ is the saturation concentration of $\mathrm{H}_{2}$ in the floc phase for a given partial pressure of $\mathrm{H}_{2}$ in the gas phase, and $m_{1}$ and $m_{2}$ are the partition coefficients for floc-membrane and membrane-electrode interfaces.

The diffusivity of $\mathrm{H}_{2}$ in the floc phase $\left(D_{f}\right)$ was determined from equation (41). Measurements of $K_{\text {sys }}$ with distilled water in the space of the attachment were compared with the measurement with floc paste in the attachment under otherwise identical conditions. As the diffusivity in the distilled water was known $\left(D_{\mathrm{H}_{2}}=5.2 \times 10^{-5} \mathrm{~cm}^{2} / \mathrm{s}\right),{ }^{30}$ $K_{\text {sys }}$ was calculated from $K_{\text {eff }}$ in distilled water and $D_{f}$ was

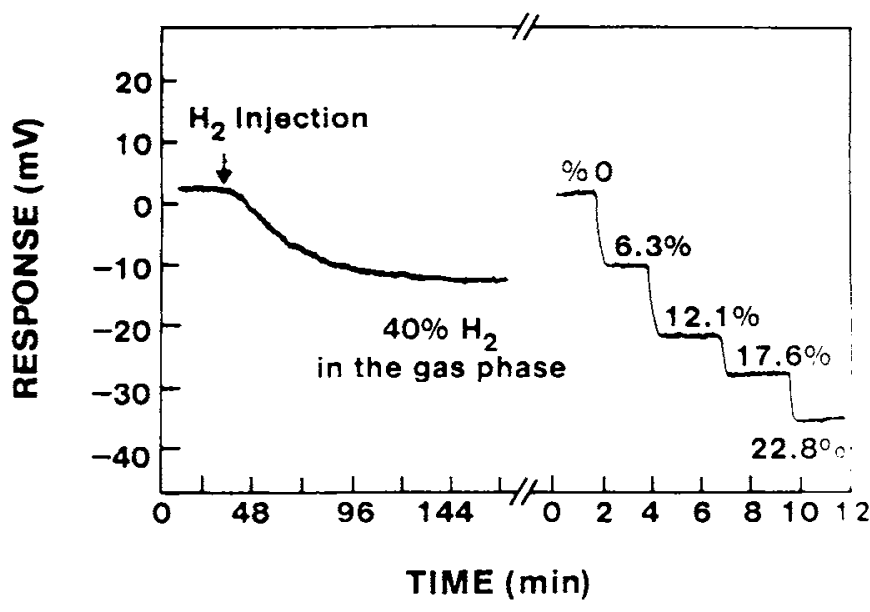

Figure 3. Example of experimental time course during determination of $\mathrm{H}_{2}$ diffusivities in digestor floc paste. Note time requirement for establishment of steady-state $\mathrm{H}_{2}$ flux to electrode and linear calibration curve in experimentally relevant concentration range. The $\mathrm{H}_{2}$ electrode setup shown in Figure 2A used in this experiment. Calibration performed after experiment without floc paste in attachment. 
then calculated accordingly from $K_{\text {sys }}$ and $K_{\text {eff }}$ in the presence of the floc paste in the attachment.

Assuming that the values of $m_{1}$ and $m_{2}$ are relatively constant and they do not change from water to floc phase, we used the same equation for a case where flocs were used instead of water under similar gas partial pressures. Since the diffusivity in water is known, the value of $K_{\text {sys }}$ is obtained from the electrode reading. Then the $K_{\text {floc }}$ and the diffusivity in the floc phase were determined. The measurements were repeated at least 3 times with fresh floc preparations.

\section{Rate Constants}

The volumetric rate constants $k_{1}$ and $k_{2}$ were determined from activity measurements of the digester flocs under substrate saturation, ${ }^{7}$ the floc protein concentrations and the specific volume $(\mu \mathrm{L} / \mathrm{mg}$ protein) of the flocs from the whey digester. The rate constants from two independent experiments recorded with 1 -year interval were within $5 \%$ deviation.

The Michealis-Menten constants for the ethanol-oxidizing acedogenic flora and $\mathrm{H}_{2}$-consuming methanogenic bacteria were used as determined in previous studies. , $^{5,13,18}$

\section{RESULTS AND DISCUSSION}

A metabolic compartmentalization of reaction pathways in microbial aggregates such as flocs, granules, or biofilms can preclude physiological reaction mechanisms and prohibit the precise measurement of kinetic parameters. This is the main reason why the physiological mechanism of syntrophic methanogenesis in microbial aggregates are presently unknown. ${ }^{21}$ Interspecies $\mathrm{H}_{2}$ gas transfer has never been directly demonstrated in nature and has only been inferred by analogy using results from defined synthetic cocultures of $\mathrm{H}_{2}$-consuming methanogens and syntrophic acetogens. ${ }^{12,31-38}$ This is dangerous because time-dependent local concentrations of reactants and intermediates could develop in natural microbial aggregates with dynamics, which are different from homogeneously dispersed, continuously mixed cultures of single cells (Fig. 1). Without knowledge of these reaction diffusion dynamics any conclusions about reactions within the aggregate are speculative.

\section{Model Parameter Estimation:}

The choice of the whey digestor floc system provided the opportunity to model and simulate interspecies hydrogen transfer based on measured parameters in a defined environment. All prevalent microbial species and their respective metabolic characteristics were known. ${ }^{18}$ The flocs could be maintained on ethanol as sole substrate for several days. ${ }^{7}$ Syntrophic ethanol oxidation to methane and acetate was the only ethanol degradation pathway. ${ }^{5}$ $D$. vulgaris and $M$. formicium, which dominated their respective trophic groups at least 100 -fold ${ }^{18}$ were the respec- tive syntrophic partners. Both species were homogeneously dispersed within the spherical flocs. ${ }^{7}$ The simplifying assumptions underlying our reaction-diffusion model (see Model Development and Analytical Methods) were thus microbiologically correct. Syntrophic ethanol conversion was accordingly modeled by two partial reactions acetogenic $\mathrm{H}_{2}$ gas production and methanogenic $\mathrm{H}_{2}$ gas consumption. ${ }^{6,10,11}$ It was assumed that the $\mathrm{H}_{2}$ transfer step was not rate limiting due to the close spatial association within the flocs (species juxtapositioning).

Precise determinations of $k_{1}, k_{2}, D_{A}, D_{B}$, and $R$ under in situ conditions were essential for realistic simulations. The volumetric reaction rate constants $k_{1}$ and $k_{2}$ were calculated from maximum conversion rates ${ }^{7}$ and the respective $K_{m}$ values. ${ }^{5,13,21}$ Two rate constant determinations from parallel chemostat ecosystems varied by less than $5 \%$ (Table II). The diffusivities for ethanol, acetate, and $\mathrm{H}_{2}$ within the floc matrix were measured under in situ conditions because values in the literature varied widely. ${ }^{28,29,39} \mathrm{~A}$ special protocol was developed to eliminate possible experimental errors due to microbial conversions and fluid channel formation (see also Figs. 2A,B). The flocs were purified to avoid contamination by free flora from the digestor. ${ }^{7}$ The stable steady-state fluxes observed in the electrode setup after $90 \mathrm{~min}$ (Fig. 3) and in the diffusion cell after $2000 \mathrm{~min}$ (Fig. 4) demonstrated the feasibility of the experimental techniques. Diffusivities for ethanol, acetate, and $\mathrm{H}_{2}$ determined for the floc paste were slightly lower than values for pure $\mathrm{H}_{2} \mathrm{O}$ (Table II) and in the same order of magnitude as determined for other microbial flocs. ${ }^{28-30,40-42}$ The digestor floc matrix therefore represented no significant physical barrier for diffusional metabolite exchange between the juxtaposed acetogenic and methanogenic bacteria. The assumption of rapid interspecies $\mathrm{H}_{2}$ transfer between juxtaposed cells inside the flocs was therefore experimentally verified.

The numerical solutions of the floc phase mass balance equations showed that qualitatively very different steadystate $\mathrm{H}_{2}$ concentration profiles could be obtained (Fig. 5). This figure was prepared assuming first-order kinetics for

Table II. Summary of constants determined and corresponding dimensionless parameters

\begin{tabular}{lll}
\hline$k_{1}$ & $6.7 \times 10^{-5} \mathrm{M}$ ethanol $/ \mathrm{s}$ & a \\
$k_{2}$ & $7.3 \times 10^{-5} \mathrm{M} \mathrm{H} \mathrm{H}_{2} / \mathrm{sec}$ & a \\
$K_{\text {eq }}^{\prime}$ & $2.4 \times 10^{-2} \mathrm{~atm}^{2}=2.56 \times 10^{-9} \mathrm{M}^{2}$ & b \\
$K_{m, A}$ & $2.5 \times 10^{-4} \mathrm{M}$ & $\mathrm{c}$ \\
$K_{m, B}$ & $6.5 \times 10^{-6} \mathrm{M}$ & $\mathrm{c}$ \\
$m_{\mathrm{H}}$ & 56.6 & \\
$D_{A}$ & $1.2 \times 10^{-6} \mathrm{~cm}^{2} / \mathrm{s}$ & $\mathrm{a}$ \\
$D_{B}$ & $1.39 \times 10^{-5} \mathrm{~cm}^{2} / \mathrm{s}$ & a \\
$D_{C}$ & $1.71 \times 10^{-6} \mathrm{~cm}^{2} / \mathrm{s}$ & a \\
$D_{E}$ & $7.6 \times 10^{-6} \mathrm{~cm}^{2} / \mathrm{s}$ & d \\
\hline
\end{tabular}

\footnotetext{
${ }^{a}$ Determined in this study. Volumetric rate constants calculated with measured apparent protein density of $0.051 \mathrm{~g} / \mathrm{cm}^{3}$ and diffusivities averaged over at least three measurements.

${ }^{\mathrm{b}}$ Based on standard free energy of $\Delta G^{\circ \prime}=9.62 \mathrm{~kJ} /$ reaction.

${ }^{c}$ From ref. 5.

${ }^{d}$ Assuming that diffusivity ratio of $\mathrm{H}_{2}$ and $\mathrm{CH}_{4}$ is as in water.
} 


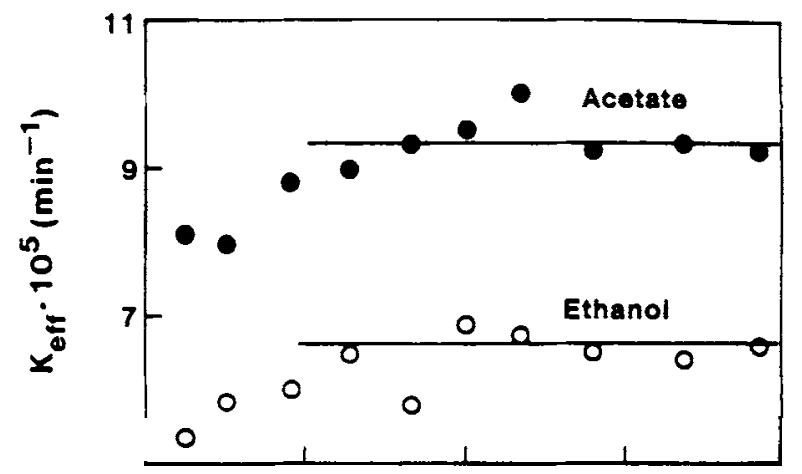

TIME (min)

Figure 4. Effective driving forces $\left(K_{\text {eff }}\right)$ for ethanol and acetate in diffusion cell in presence of floc paste. Note stable values at $2000 \mathrm{~min}$ after initial transient behavior. Diffusion cell shown in Figure $2 B$ used for determinations.

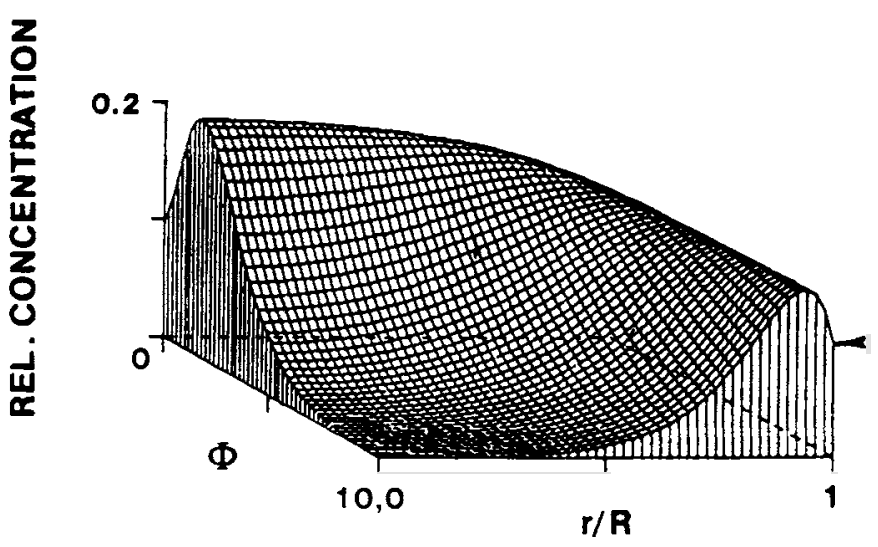

\section{RADIALCOORDINATE}

Figure 5. Sensitivity analysis of model predictions for varying Thiele moduli. Thiele modulus for reaction (a) in model was varied and resulting $\mathrm{H}_{2}$ profiles in floc matrix shown. Simulation conducted for first-order reaction mechanism for acetogenic and methanogenic partial reactions. Experimentally determined parameters for digestor flocs used. Arrow shows bulk concentration of $\mathrm{H}_{2}(2.5 \mu M)$.

both reactions, which is realistic for most stable biomethanation reactors under normal operation conditions with partial pressures of $\mathrm{H}_{2}$ gas and intermediary metabolite concentrations below the $K_{m}$ values of the important metabolic groups. ${ }^{5,13,21}$ Mildly diffusion-controlled systems at values of $\phi_{2}$ close to 1 would show a significant accumulation of $\mathrm{H}_{2}$ gas throughout the floc phase due to the fast ethanol oxidation. In the strongly diffusion-controlled case $\left(\phi_{2}>10\right), \mathrm{H}_{2}$ gas accumulation could occur only at the periphery of the floc, whereas the diffusion-controlled ethanol supply would result in significantly lower steadystate $\mathrm{H}_{2}$ gas concentrations at the center. Such variations in the Thiele modulus could be caused in nature by organic shock loads or microbial growth (larger diameter or higher volumetric reaction rate constant) and decay (lower volumetric reaction rate constant).

\section{Simulation of Fermentation Time Courses}

Local concentrations of $\mathrm{H}_{2}$ gas, ethanol, or acetate control the volumetric biochemical activity of acetogenic and methanogenic bacteria inside the flocs. The ethanol-dependent $\mathrm{H}_{2}$ and acetate production by digestor flocs was simulated accordingly in a mass-balanced fermentation time course for an experimental system consisting of flocs, the bulk phase, and the gas phase (Fig. 6). If the model was realistic, its predicted dynamics should be consistent with observed experimental results. ${ }^{7}$ Experimentally measured rates of ethanol oxidation were used as the lead parameter and the production of acetate and $\mathrm{H}_{2}$ gas as the model response (Fig. 6). The experimentally measured $\mathrm{H}_{2}$ gas and acetate levels were predicted within $10 \%$ error. In the original experiments one-half of the floc preparation was disrupted into small fragments and incubated separately. The model predicted correctly the increased $\mathrm{H}_{2}$ gas production from the changed diameter (Thiele modulus) of the floc fragments. It should be noted that all simulations were completely based on measured parameters. Thus the model was capable of relating simulated syntrophic reaction dynamics and concentration profiles inside the flocs with the measured parameters of the floc system and measured composition changes outside the flocs. These results showed that the measured compartmentalization of the interspecies electron transfer inside the flocs ${ }^{7}$ can be conclusively explained as a consequence of microbial aggregation and syntrophic metabolic communication via simple diffusion and reaction mechanisms between juxtaposed cells.

The capabilities of the reaction-diffusion model were demonstrated by simulation of another experiment ${ }^{7}$ with intact digestor flocs from a second digestor (Fig. 7). A good agreement between ethanol metabolism and predicted $\mathrm{H}_{2}$ gas levels in the experimental vials was found. Note that headspace-liquid ratios and protein concentrations were different from the previous simulation (Fig. 6). However, the production of $\mathrm{H}_{2}$ gas could be predicted with similar precision.

\section{$\mathrm{H}_{2}$ Concentration Profiles Inside Flocs}

A measurement of $\mathrm{H}_{2}$ gas concentrations inside microbial flocs is impossible due to the lack of sensitive microprobes. The agreement between experimental and predicted data (Figs. 6 and 7) made it possible to simulate the steady-state $\mathrm{H}_{2}$ gas concentration profiles in the floc matrix using the determined dimensionless model parameters (Table II). The analysis was used to decide whether the flocs would display higher ${ }^{7}$ or lower ${ }^{19}$ internal $\mathrm{H}_{2}$ gas levels during active syntrophic ethanol degradation. The Thiele moduli $\phi_{2}$ and $\psi_{2}$ indicated a mild diffusion control of the floc reaction system (Table III and Fig. 5) resulting in a continuous $\mathrm{H}_{2}$ profile with elevated $\mathrm{H}_{2}$ gas levels in the floc matrix (Fig. 8A). The predicted $\mathrm{H}_{2}$ gas profiles were flat and independent of the external dissolved $\mathrm{H}_{2}$ concentration (Fig. 8A), "Bathtub"-shaped concentration profiles as a result of low $\mathrm{H}_{2}$ environments inside the 


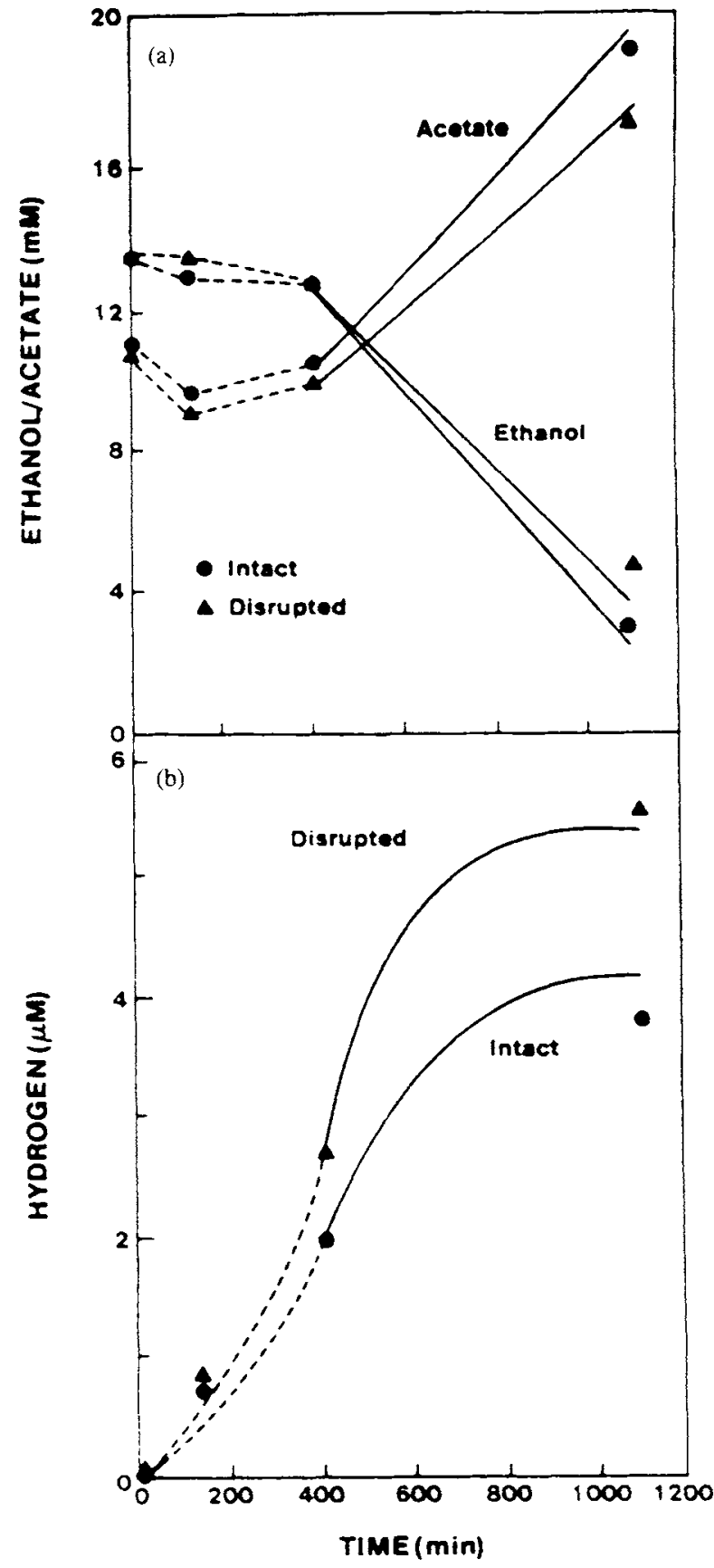

Figure 6. Comparison of measured (symbols) and simulated (lines) ethanol, acetate, and $\mathrm{H}_{2}$ concentrations for syntrophic conversions by intact and disrupted flocs. Experiments with starved digestor flocs described elsewhere (ref. 7) simulated from estimated parameters in Table III. The $\mathrm{H}_{2}$ and acetate concentrations before $400 \mathrm{~min}$ could not be simulated due to inconsistencies in experimental conversion rate arising from adaptation of bacteria into fresh medium (lag phase).

flocs ${ }^{21}$ were not predicted by the diffusion reaction model. The calculated dissolved $\mathrm{H}_{2}$ gas concentration at the center of the flocs $(5.5 \mu M)$ could support only a half-maximum saturation of the methanogenic $\mathrm{H}_{2}$ consumption $\left(K_{m}=\right.$ 4-6 $\mu M) .{ }^{19}$ A complete saturation of methanogenic $\mathrm{CO}_{2}$ reduction by $\mathrm{H}_{2}$ gas as measured during the syntrophic ethanol oxidation inside the flocs ${ }^{23}$ would require approxi-

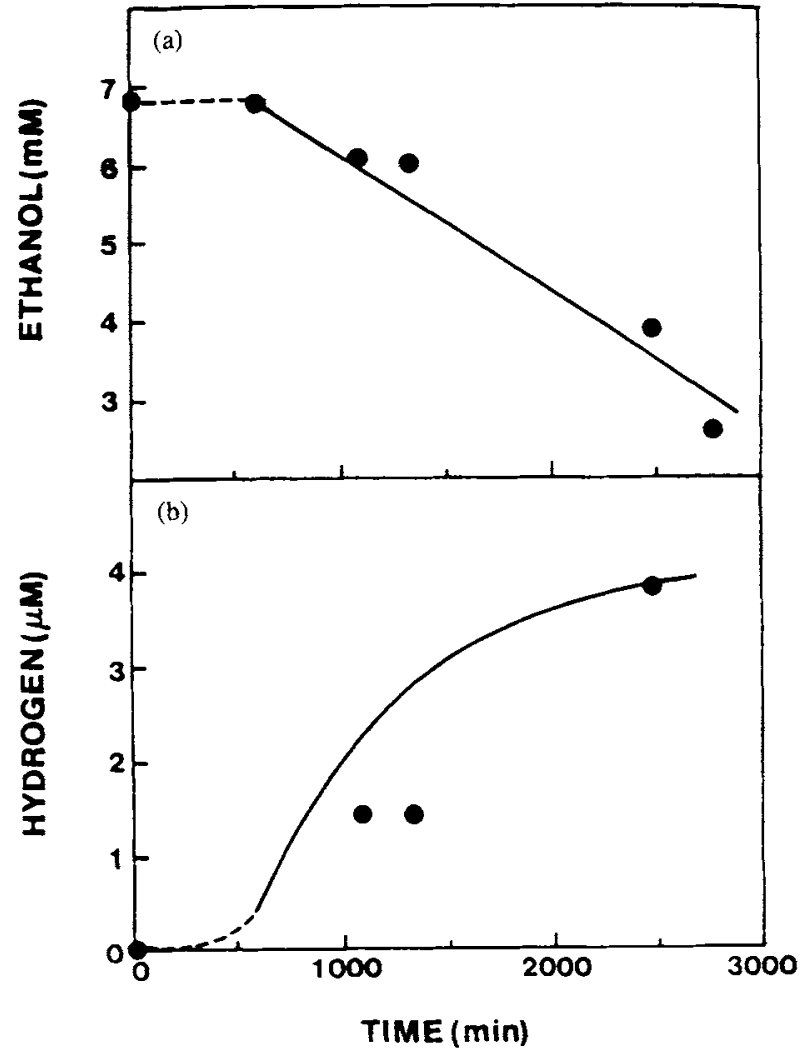

Figure 7. Comparison of measured (symbols) and simulated (lines) ethanol and $\mathrm{H}_{2}$ concentrations during syntrophic conversion by fresh flocs. Experiments described elsewhere (ref. 7) simulated using estimated parameters in Table III.

mately 6-fold higher internal $\mathrm{H}_{2}$ gas levels. This difference supported the earlier conclusion ${ }^{23}$ that $\mathrm{H}_{2}$ gas might not be a major physiological intermediate of interspecies electron transfer in these flocs. The free energies for acetogenic ethanol oxidation inside the floc phase could be calculated from the simulated concentration profiles (Table IV). The model predicted free energies, which were less exergonic in the floc phase than for a conversion outside the digestor flocs $(-18$ to $-28 \mathrm{~kJ} / \mathrm{rxn}) .{ }^{24}$ Floc-associated growth of the acetogenic bacteria should then be bioenergetically disadvantageous. But a more than three-fold preference of the syntrophic ethanol-oxidizing bacteria for the floc fraction was demonstrated experimentally in the digestor at steady state. ${ }^{7}$ The digestor flocs showed a size distribution between approximately 50 and $150 \mu \mathrm{m}$ radius $(\mathrm{J}$. H. Thiele,

Table III. Parameters used in simulations for data by Thiele et al. ${ }^{2}$ : dimensionless groups.

\begin{tabular}{rlr}
$\phi^{2}$ & $=5.55($ intact); & \\
$\psi^{2}=80.8($ intact); & & 0.056 (disrupted) \\
$\kappa$ & $=60.6$ & \\
$\alpha_{1}$ & $=0.086$ & \\
$\alpha_{2}$ & $=0.70$ & \\
$\alpha_{3}$ & $=0.54$ & \\
$\gamma$ & $=0.026$ & \\
\hline
\end{tabular}

${ }^{\mathrm{a}}$ Reference 7. 
Table IV. Predicted concentrations and free energies at center of microbial flocs during ethanol oxidation.

\begin{tabular}{|c|c|c|c|c|c|}
\hline Condition & $\begin{array}{l}\text { Time } \\
(\min )\end{array}$ & $\begin{array}{c}\Delta G \\
(\mathrm{~kJ} / \text { reaction })\end{array}$ & $\begin{array}{c}\mathrm{H}_{2} \text { partial } \\
\text { pressure } \\
(\mathrm{Pa})\end{array}$ & $\begin{array}{l}\text { Ethanol } \\
(\mathrm{m} M)\end{array}$ & $\begin{array}{c}\text { Acetate } \\
(\mathrm{m} M)\end{array}$ \\
\hline Intact & 0 & -15.7 & 820 & 13.3 & 11.0 \\
\hline Disrupted & 0 & -36.3 & 15.15 & 13.5 & 10.7 \\
\hline Intact & 136 & -16.5 & 755 & 12.7 & 9.5 \\
\hline Disrupted & 136 & -23.1 & 203.2 & 13.5 & 9.0 \\
\hline Intact & 405 & -15.7 & 828 & 12.7 & 10.7 \\
\hline Disrupted & 405 & -20.7 & 356 & 12.6 & 10.0 \\
\hline Intact & 1100 & -11.3 & 705 & 2.8 & 19.2 \\
\hline Disrupted & 1100 & -13.7 & 589 & 4.7 & 17.0 \\
\hline
\end{tabular}

unpublished). Figure 8B shows therefore the influence of a floc diameter variation at saturating ethanol concentrations (13.5mM) and $2.5 \mu M \mathrm{H}_{2}$. Significant diffusion limitation of the ethanol oxidation occurred only in flocs above $800 \mu \mathrm{m}$ diameter. Only $11 \%$ of the floc volume exhibited $\mathrm{H}_{2}$ levels below $2.5 \mu M$ even at a floc diameter of $1040 \mu \mathrm{m}$.

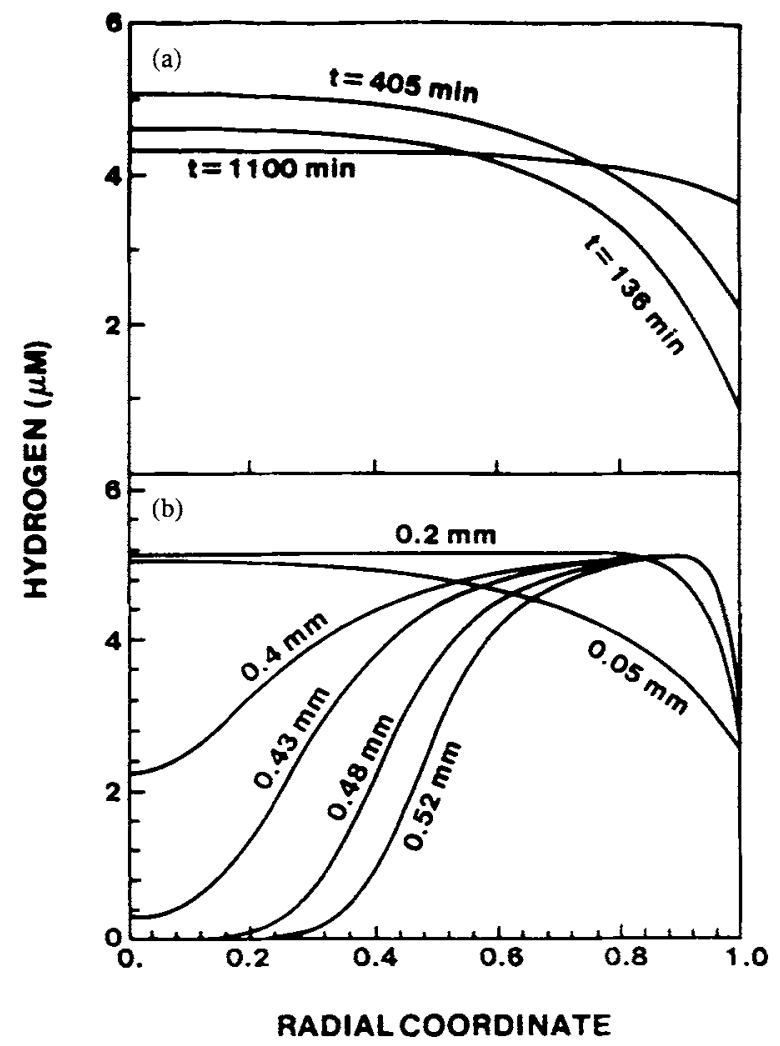

Figure 8. Hydrogen gas profiles inside floc matrix at high ethanol and $\mathrm{H}_{2}$ concentration in bulk. (A) Time-dependent $\mathrm{H}_{2}$ profiles in flocs during experiment shown in Figure 6. Flocs of $100 \mu$ m diameter were simulated. Ethanol concentration decreased during this experiment with increasing time from 13.5 to $3.5 \mathrm{mM}$. Note elevated $\mathrm{H}_{2}$ concentrations inside flocs at any time. (B) Sensitivity analysis of $\mathrm{H}_{2}$ profiles with increasing floc diameters. Thiele modulus varied by simulating floc radii, which increased from 0.05 to $0.2,0.4,0.43,0.48$, and $0.52 \mathrm{~mm}$ at ethanol and hydrogen concentrations in bulk of $13.5 \mathrm{mM}$ and $2.5 \mu M$, respectively. Note sharp transition in dynamic behavior of reaction-diffusion system at floc radii above $0.4 \mathrm{~mm}$. Flocs changed from reaction-controlled to diffusioncontrolled ethanol metabolism indicated by "bathtub"-shaped $\mathrm{H}_{2}$ concentration profiles.
Thus potentially lower $\mathrm{H}_{2}$ levels inside large flocs were quantitatively unimportant. The floc diameter range where diffusion limitations became apparent is in an approximate agreement with experimental data derived from granular sludge syntrophically degrading volatile fatty acids. ${ }^{43} \mathrm{~A}$ diffusion controlled metabolism was observed in this system at diameters above $1500 \mu \mathrm{m}$, which is consistent if one considers the $50 \%$ reduced specific methane productivity of the granular sludge (see what follows).

\section{Conclusions for Syntrophic Methanogenesis in Nature}

The maximum syntrophic methane productivity of the whey digestor flocs $\left(0.14 \mathrm{~mol} \mathrm{CH}_{4} / \mathrm{g} \text { protein day }\right)^{7}$ was in the same order of magnitude as determined for ecoengineered syntrophic biomethanation catalysts $(0.16 \mathrm{~mol}$ $\mathrm{CH}_{4} / \mathrm{g}$ protein day $)^{44}$ or UASB granular sludge $(0.07 \mathrm{~mol}$ $\mathrm{CH}_{4} / \mathrm{g}$ protein day). ${ }^{45}$ It was thus jusified to use the diffusion reaction model of the digestor flocs to study the consequences of aggregation for the dynamics of syntrophic metabolism in several different practical situations. The levels of $\mathrm{H}_{2}$ in anaerobic digestors are usually between 0.20 and $2.5 \mu \mathrm{M}^{5,19,20}$ Ethanol levels between 10 and $100 \mu M$ have been reported. ${ }^{5,19.20}$ Thus $\mathrm{H}_{2}$ and ethanol profiles inside the flocs were also simulated for low substrate concentrations assuming flocs of $100 \mu \mathrm{m}$ diameter (Fig. 9). Inward-oriented concentration gradients for ethanol and $\mathrm{H}_{2}$ and lower concentrations in the center of the aggregate were a consequence of the low substrate levels in the bulk phase outside the flocs (Fig. 9), not of an extremely fast $\mathrm{H}_{2}$ turnover. The methanogenic $\mathrm{H}_{2}$ turnover rate in the flocs under these conditions was $0.2-0.01$ of the turnover rate in the presence of saturating ethanol concentrations (see Table II and Figs. 8A,B). The $\mathrm{H}_{2}$ partial pressure at $10 \mu M$ ethanol and $2.5 \mu M$ hydrogen would be below $10 \mathrm{~Pa}$ in $20-50 \%$ of the floc volume. This is close to the suggested threshold $\mathrm{H}_{2}$ pressure of 7-10 $\mathrm{Pa}$ for methanogenic $\mathrm{H}_{2}$ consumption. ${ }^{46}$ Methanogenic bacteria would be starving under these conditions. Similar considerations apply to microbial aggregates in freshwater sediments. The $\mathrm{H}_{2}$ gas levels inside $100-\mu$ m-diameter flocs (Fig. 10) would be higher than in the interstitial water at dissolved $\mathrm{H}_{2}$ levels below $0.05 \mu \mathrm{M}$ and ethanol levels above $70 \mu \mathrm{M}$ as measured in Lake Mendota sediments. ${ }^{47}$ Lower levels of $\mathrm{H}_{2}$ 


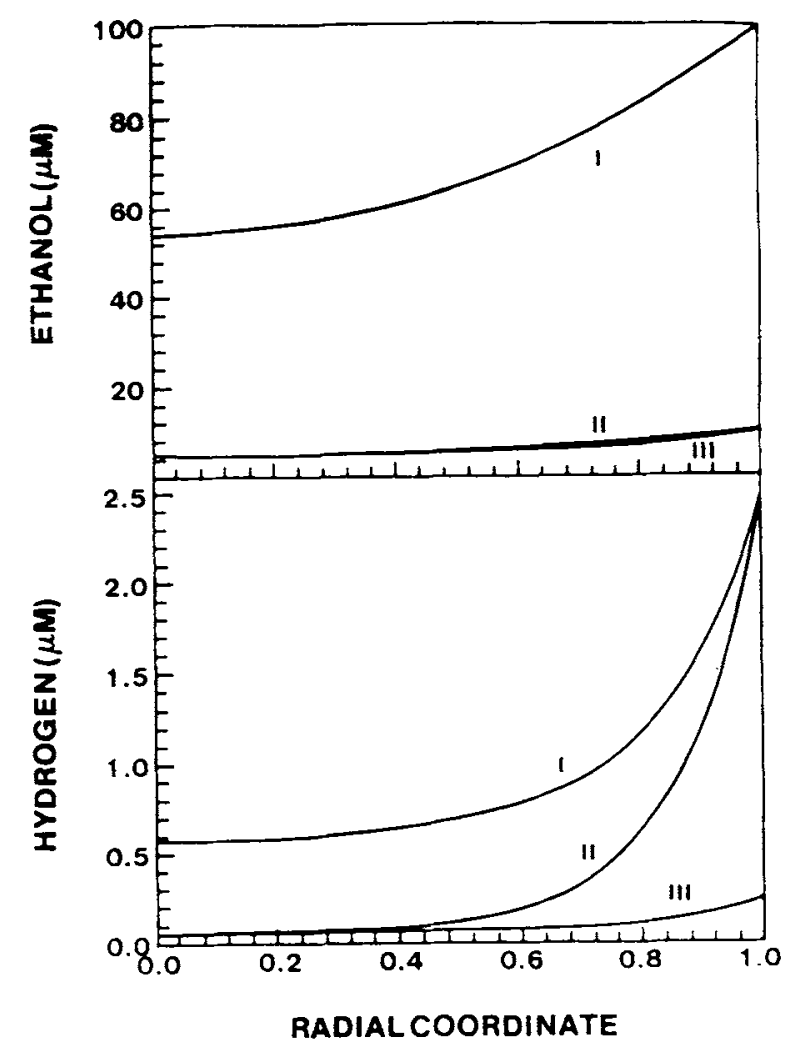

Figure 9. Syntrophic ethanol conversion at low substrate concentrations. Three different physiological meaningful $\mathrm{H}_{2}$ and ethanol concentrations used for simulations. Note inward-oriented $\mathrm{H}_{2}$ and ethanol profiles in all three situations. The $\mathrm{H}_{2}$ levels in Cases II and III inside floc close to metabolic limit of $\mathrm{H}_{2}$ consuming methanogens: (I) $100 \mu M$ ethanol, $2.5 \mu M \mathrm{H}_{2}$; (II) $10 \mu M$ ethanol, $2.5 \mu M \mathrm{H}_{2}$; (III) $10 \mu M$ ethanol, $0.2 \mu M \mathrm{H}_{2}$

would be observed in larger flocs, but large portions of these aggregates would be below the metabolic threshold levels of approximately $5 \mu M$ ethanol and $0.05 \mu M \mathrm{H}_{2}$ respectively (Fig. 10).

Clear experimental proof for interspecies $\mathrm{H}_{2}$ transfer in natural ecosystems is presently lacking. The $\mathrm{H}_{2}$ gas is believed to be inhibitory for the syntrophic acetogenic metabolism due to unfavorable thermodynamics at high $\mathrm{H}_{2}$ partial pressures, and this is believed to be the reason for the requirement of $\mathrm{H}_{2}$-consuming methanogenic bacteria in syntrophic associations. ${ }^{10-12}$ But this relationship has so far only been indirectly demonstrated in defined mixed cultures of nonaggregated bacteria under artificial laboratory conditions. The model simulations in this study point for the first time at important mechanistic inconsistencies between the biological theory of the interspecies $\mathrm{H}_{2}$ transfer and experimental and theoretical biochemical consequences of simple diffusion reaction mechanisms. Syntrophic aggregates with lower internal $\mathrm{H}_{2}$ partial pressures, which were postulated for sediments and digestors as mechanism to avoid a presumed $\mathrm{H}_{2}$ inhibition of syntrophic acetogens $^{19}$ by high methanogenic activities, occur only under diffusion-limited conditions inside the aggregates. Such

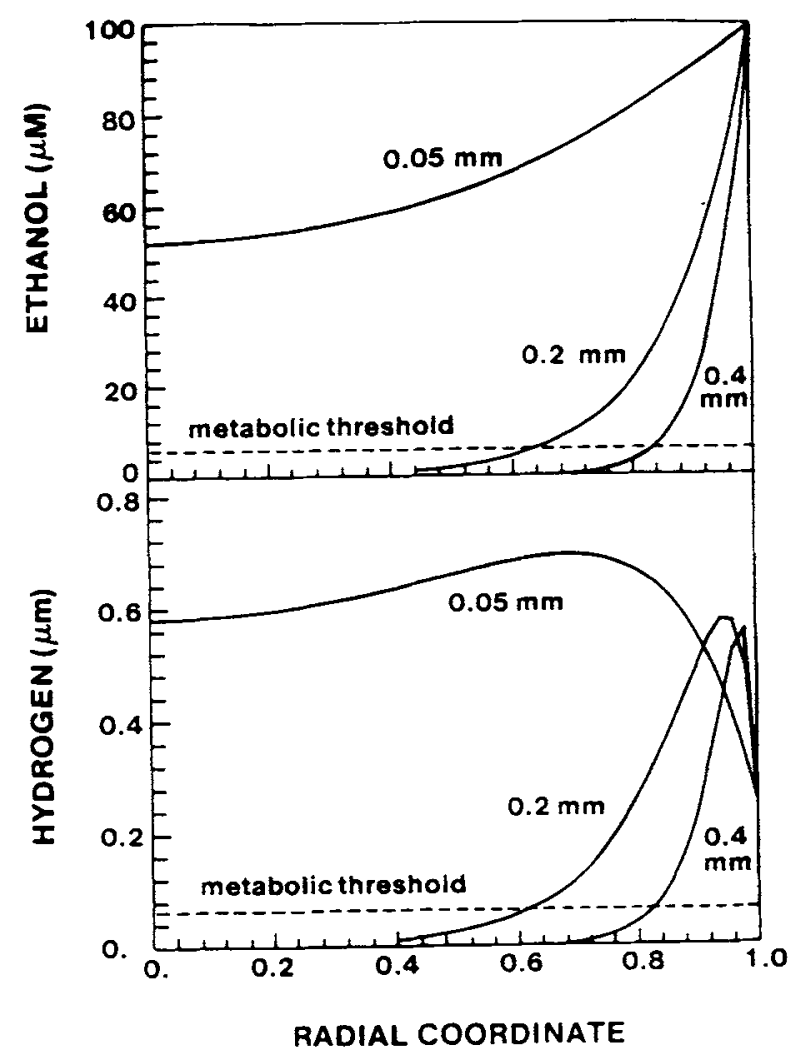

Figure 10. Sensitivity analysis of syntrophic reaction dynamics at low substrate concentrations. Metabolic situation of $100 \mu M$ ethanol and $0.25 \mu M \mathrm{H}_{2}$ in bulk assumed. Concentration profiles for $\mathrm{H}_{3}$ and ethanol simulated for flocs of 100,400 , and $800 \mu \mathrm{m}$ diameter. Note that steadystate metabolite concentrations inside flocs mostiy below metabolic threshold at large floc diameters. Microbial growth could only occur at surface of aggregate. Also note "bathtub"-shaped concentration profiles under these conditions.

diffusion limitations would result in microbial starvation, not in higher microbial actitivies, as postulated. The simulations show, in addition, that the reaction diffusion dynamics of $\mathrm{H}_{2}$ transfer mechanisms do not fit to the predicted bioenergetic and measured kinetic requirements of acetogens and methanogens. The simulated hydrogen profiles inside the flocs under ethanol saturation reached only approximately one-fifth of the concentration levels required to achieve the experimentally measured saturation of methanogenic $\mathrm{CO}_{2}$ reduction. ${ }^{23}$ But the same $\mathrm{H}_{2}$ levels would be more than 20 times too high to provide thermodynamically favorable conditions for the ethanol-oxidizing acetogens. Nevertheless, methanogens and ethanol-oxidizing acetogens were preferentially floc associated in this digestor. ${ }^{7}$ We presented elsewhere experimental evidence for an alternative mechanism of interspecies electron transfer in these digestor flocs, ${ }^{23}$ the formate-bicarbonate electron shuttle loop. The $\mathrm{H}_{2}$ gas is only a syntrophic side product according to this mechanism. Formate is the major reduced syntrophic intermediate, which is produced by $D$. vulgaris via reduction of bicarbonate $\left(\mathrm{CO}_{2}\right.$ reduction). This coupling mechanism provides extra free energy to the syntrophic acetogens by the huge bicarbonate-formate ratio of 
anaerobic ecosystems $(1000-10,000)$. Formate-utilizing methanogens, in this case $M$. formicium, cleave formate to methane and bicarbonate and recycle bicarbonate as the interspecies electron carrier. Formate is also cleaved by formate- $\mathrm{H}_{2}$ lyase to $\mathrm{H}_{2}$ and $\mathrm{CO}_{2}$, but only as a side reaction outside the flocs. This reaction produces the measured $\mathrm{H}_{2}$ gas. It results in two different pools of syntrophic reducing equivalents, a formate pool shared by juxtaposed acetogens and methanogens inside the flocs and a $\mathrm{H}_{2}$ gas pool in the environment. The apparent saturation of methanogenic $\mathrm{CO}_{2}$ reduction at low $\mathrm{H}_{2}$ gas levels can be explained by formate utilization within the flocs.

The importance of interspecies electron transfer as a concept for syntrophic methanogenesis ${ }^{10,11}$ is unaffected by these results. Formate and $\mathrm{H}_{2}$ are equivalent in their redox properties. Thus compound $\mathrm{B}$ in our model can be easily substituted by formate without changing the model structure. A refined model version incorporating the formate $\mathrm{H}_{2}$ lyase reaction outside the flocs using measured values for $k_{2}, K_{m, B}, D_{B}$, and the formate- $\mathrm{H}_{2}$ lyase activity could predict the measured formate and $\mathrm{H}_{2}$ production, ethanol degradation, and acetate formation within $5 \%$ error. ${ }^{23,48}$ Thus interspecies electron transfer via reduced acetogenic fermentation products demonstrated by many excellent experiments $^{10-12,31-38}$ is still a valid microbiological concept. However, the physiological reduced intermediate within microbial aggregates might be formate instead of $\mathrm{H}_{2}$ gas.

S. S. O. was supported by a traineeship grant from the Michigan Biotechnology Institute, J. H. T. by a research fellowship from the Deutsche Forschungsgemeinschaft (TH 336/1-1), and the experimental research by a grant from Michigan Biotechnology Institute. The authors are grateful to I. Gregory Zeikus for the permission to use his laboratory facilities at the Michigan State University. We thank Hans Grethlein for valuable comments during the preparation of the manuscript.

\section{NOMENCLATURE}

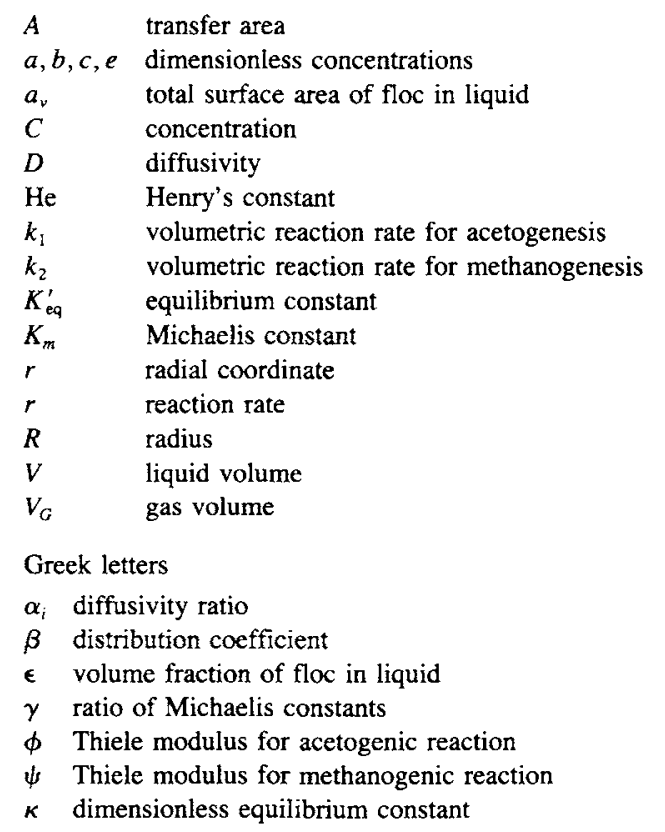

$\xi$ dimensionless coordinate, $r / R$

$\tau$ dimensionless time, $\epsilon D_{A} t / R^{2}$

Subscripts

A ethanol

$B$ hydrogen

$C$ acetate

$E$ methane

o bulk

$\begin{array}{ll}\text { Superscripts } \\ O & \text { bulk } \\ i & \text { initial } \\ g & \text { gas } \\ l & \text { liquid }\end{array}$

\section{References}

1. F. G. Pohland and S. H. Harper, in Anaerobic Digestion, Proceedings of the Fourth International Symposium on Anaerobic Digestion, Guangzhou, China, 1985.

2. H. Sahm, Adv. Bioch. Eng. Biotechnol., 29, 84 (1984).

3. G. Lettinga, A. F. M. van Vellsen, S. W. Hobma, W. de Zeeuw, and A. Klapwigk, Biotechnol. Bioeng., 22, 1699 (1980).

4. J. S. Jeris and P. L. McCarty, Wat. Pol. Contr. Fed., 37, 178 (1965).

5. M. Chartrain and J. G. Zeikus, Appl. Environ. Microbiol., 51, 180 (1986).

6. R. Mah, Philos. Trans. Roy. Soc. Lond., B297, 599 (1982).

7. J. H. Thiele, M. Chartrain, and J. G. Zeikus, Appl. Environ. Microbiol., 54, 10 (1987).

8. W. E. Balch, G. E. Fox, L. J. Magrum, C. R. Woese, and R. S. Wolfe, 43, 260 (1979).

9. W. J. Jones, D. P. Nagle, and W. P. Whitman, Microbiol. Rev., 53, 135 (1987).

10. M.J. Wolin, in Microbiol. Production and Utilization of Gases, H. G. Schlegel, G. Gotschalk, and N. Pfenning, Ed. E. Goltz, Göttingen F.R. Germany (1975), p. 141.

11. M. J. Wolin and T. L. Miller, ASM News, 48, 561 (1982).

12. H. F. Kaspar and Wuhrmann, Microbiol. Ecol., 4, 241 (1978).

13. J. Chartrain, L. Bhatnagar, and J. G. Zeijus, Appl. Environ. Microbiol., 51, 188 (1987).

14. J. C. Young and P. L. McCarty, J. Wat. Poll. Contr. Fed., 41, R160 (1969).

15. G. Lettinga, W. de Zeeuw, P. L. Hulshohh, W. Wiegant, and A. Rinzema, "Anaerobic Digestions 1985. Proceedings of the Fourth International Symposium on Anaerobic Digestion," Guangzhou, China (1985), p. 279.

16. E. W. Thiele, Ind. Eng. Chem., 31, 916 (1939).

17. B. Atkinson, Biochemical Reactors (Pion Ltd., London, 1939).

18. M. Chartrain and J. G. Zeikus, Appl. Environ. Microbiol., 51, 188 (1986).

19. R. Conrad, B. Schink, and T. J. Phelps, FEMS Microbiol. Ecol., 38, 353 (1986).

20. R. Conrad, T. J. Phelps, and J. G. Zeikus, Appl. Environ. Microbiol., 50, 1285 (1985).

21. J. H. Thiele and J. G. Zeikus, in Handbook on Anaerobic Fermentations, L.E. Erickson and D. Fung, Eds., (Marcel Dekker, New York, 1988), Chapter 17.

22. B. R. Boone, Appl. Environ. Microbiol., 48, 122 (1984).

23. J. H. Thiele and J. G. Zeikus, Appl. Environ. Microbiol., 54, 20 (1988).

24. S. S. Ozturk, B. Palsson, J. H. Thiele, and J. G. Zeikus, Biotechnology Processes: Scale-up and Mixing, C. S. Ho and J. Y. Oldshue (Eds.) (American Institute of Chemical Engineers, New York, 1986), p. 142.

25. R. Aris, The Mathematical Theory of Diffusion and Reaction in Permeable Catalysts (University Press, Oxford, 1975).

26. J.E. Bailey and D.F. Ollis, Biochemical Engineering Fundamentals, 
2nd ed. (McGraw-Hill, New York, 1986).

27. B. H. Carnahan, H. A. Luther, and J. O. Wilkes, Applied Numerical Methods, (Wiley, New York, 1969).

28. K. Akita, Ind. Eng. Chem. Fund., 20, 89 (1981).

29. J. L. Kwang and C. S. Ho, Biotechnol. Bioeng., 27, 1495 (1985).

30. T. K. Sherwood, R. L. Pigford, and C. R. Wilke, Mass Transfer (McGraw-Hill, New York, 1975).

31. C. A. Reddy, M. P. Bryant, and M. J. Wolin, J. Bacteriol., 109, 539 (1972).

32. D. R. Boone and M. P. Bryant, Appl. Environ. Microbiol., 40, 626 (1980).

33. M. P. Bryant, E. A. Wolin, M. J. Wolin, and R. S. Wolfe, Arch. Microbiol., 59, 20 (1967).

34. M. P. Bryant, L. L. Campbell, C. A. Reddy, and M. A. Crabill, Appl. Environ. Microbiol., 33, 1162 (1977).

35. E. L. Ianotti, P. Kafkewitz, M. J. Wolin, and M. P. Bryant, J. Bacteriol., 114, 1231 (1973).

36. M. J. Mcinemey, M. P. Bryant, R. B. Hespell, and J. W. Costerton, Appl. Environ. Microbiol., 41, 1029 (1981).

37. D. O. Mountfort and M. P. Bryant, Arch. Microbiol., 133, 249 (1982).

38. S. H. Zinder and M. Koch, Arch. Microbiol., 138, 263 (1984).

39. R. L. Droste and K. J. Kennedy, Biotechnol. Bioeng., 28, 1713 (1986).

40. K. Williamson and P. L. McCarty, J. Wat. Poll. Contr. Fed., 48, 281 (1976).

41. M. T. Onuma, T. Omura, T. Umita, and J. Aizawa, J., Biotechnol. Bioeng., 27, 1533 (1985)
42. B. J. M. Hannoun and G. Stephanopoulos, Biotechnol. Bioeng., 28, 829 (1986).

43. J. Tramper, J. M. van Groenstign, K. Ch. A. M. Luyben and L. W. Hulshof, in Innovations in Biotechnology, E. H. Houwink and R. R. van der Meer, Ed. (Elsevier, Amsterdam, 1984).

44. J. H. Thiele and J. G. Zeikus, Biotechnol. Bioeng., in press.

45. J. Dolfing, Appl. Microbiol. Biotechnol., 22, 77 (1985).

46. D. R. Lovley, Appl. Environ. Microbiol., 49, 1530 (1985).

47. T. J. Phelps and J. G. Zeikus, Appl. Environ. Microbiol., 50, 1285 (1985).

48. J. H. Thiele, S. S. Ozturk, B. Palsson, and J. G. Zeikus, Biotechnol. Bioeng., in preparation.

49. B. Atkinson, in Microbiol Adhesion and Aggregation, K. C. Marshall, Ed. Springer-Verlag, New York 1984, p. 351.

50. B. Atkinson and I. S. Daoud, Trans Inst. Chem. Eng., 46, T16 (1968).

51. B. Atkinson and I. J. Davies, Trans. Inst. Chem. Eng., 52, 248 (1974).

52. B. Atkinson and S. Y. How, Trans. Inst. Chem. Eng., 52, 260 (1974).

53. B. E. Rittmann and P. L. McCarty, J. Environ. Eng. Div. Proc. Am. Soc. Civ. Eng., 107, 831 (1981).

54. K. Williamson and P. L. McCarty, J. Wat. Poll., Contr. Fed., 48, 9 (1976).

55. J. D. Bryers, Biotechnol. Bioeng., 27, 638 (1985).

56. P. Moletta, D. Vernier, and G. Albagnac, Wat. Res., 20, 427 (1986).

57. A. Dalla Torre and G. Stephanopoulos, Biotechnol. Bioeng., 28, 1138 (1986). 